\title{
The DRUID study: racism and self-assessed health status in an indigenous population
}

\author{
Yin C Paradies ${ }^{1 *}$ and Joan Cunningham ${ }^{2}$
}

\begin{abstract}
Background: There is now considerable evidence from around the world that racism is associated with both mental and physical ill-health. However, little is known about the mediating factors between racism and ill-health. This paper investigates relationships between racism and self-assessed mental and physical health among Indigenous Australians as well as potential mediators of these relationships.

Methods: A total of 164 adults in the Darwin Region Urban Indigenous Diabetes (DRUID) study completed a validated instrument assessing interpersonal racism and a separate item on discrimination-related stress. Selfassessed health status was measured using the SF-12. Stress, optimism, lack of control, social connections, cultural identity and reactions/responses to interpersonal racism were considered as mediators and moderators of the relationship between racism/discrimination and self-assessed health status.

Results: After adjusting for socio-demographic factors, interpersonal racism was significantly associated with the SF-12 mental (but not the physical) health component. Stress, lack of control and feeling powerless as a reaction to racism emerged as significant mediators of the relationship between racism and general mental health. Similar findings emerged for discrimination-related stress.

Conclusions: Racism/discrimination is significantly associated with poor general mental health among this indigenous population. The mediating factors between racism and mental health identified in this study suggest new approaches to ameliorating the detrimental effects of racism on health. In particular, the importance of reducing racism-related stress, enhancing general levels of mastery, and minimising negative social connections in order to ameliorate the negative consequences of racism.
\end{abstract}

\section{Background}

Racism is an organised system that labels some ethnic/ racial groups as inferior to others and differentially allocates desirable societal resources to the superior ethnic/ racial groups (Bonilla-Silva 1997). Racism can be defined as avoidable and unfair phenomena that result in inequality of resources, opportunities or benefits among racial/ethnic groups. It can be expressed through stereotypes (racist beliefs), prejudice (racist emotions) or discrimination (racist behaviours and practices) [1].

Regardless of its health, social or economic effects, racism is first and foremost a breach of human rights as enshrined in various national and international laws. Nonetheless, racism is also a social determinant of

\footnotetext{
* Correspondence: yinp@unimelb.edu.au

'McCaughey Centre, Melbourne School of Population Health, University of Melbourne, Melbourne, Australia

Full list of author information is available at the end of the article
}

health that we need to understand in order to inform programs and policies to ameliorate its detrimental effects [2].

In recent years, the study of racism and health has emerged as an area of public health research. At the end of 2007, reviews identified over 250 publications examining racism as a determinant of mental and physical health and/or health behaviours, revealing strong associations between self-reported racism and ill-health among minority groups in developed countries [3-5]. These associations remained after adjusting for a range of confounders and occurred in longitudinal as well as cross-sectional studies, suggesting that racism precedes ill-health rather than vice versa. The most consistent finding has been the association between racism and mental ill-health [3-5].

It is important to note that this body of literature has predominately focused on the relationship between self-

\section{Biomed Central}


reported (also known as perceived) racism and health. This constitutes only one avenue through which racism influences health. More generally, racism can act through a number of pathways to affect mental and physical health, including via: reduced access to healthpromoting social determinants of health such as education and employment, induced acute and chronic stress, reduced self efficacy, self esteem, increased uptake of substance use, higher rates of self harm, reduced quality and quantity of actual and perceived social support, and detrimental effects on cultural identity [6,7].

Exposure to racism as a form of stress can give rise to a range of factors that contribute to ill-health $[8,9]$. These factors include negative emotional states, reduced self-esteem, low self-efficacy and reduced self-control as well as pessimism, aggression, hyper-vigilance, and rumination [3-5]. Racism has also been linked to hypertension [10], cortisol dysregulation [11-13], sleep disturbance [14,15], obesity [16-18], and smoking [19-23] as well as alcohol and illicit drug use [23-28]. These factors have, in turn, been associated with poor mental and physical health [5,29-31].

To date, racism and health literature has focused primarily on the United States and specifically African Americans [3,4]. In addition, little is known about the causal pathways leading from racism to ill-health [32]. This paper adds to existing scholarship by examining the relationship between racism and self-assessed health in an indigenous population outside the United States-in particular, Indigenous Australians.

Indigenous (also known as Aboriginal) Australians constitute 2.4 per cent of the Australian population and suffer high rates of unemployment and incarceration, low income, sub-standard housing and a high burden of ill-health and mortality, including a life expectancy 9-12 years less than other Australians [33]. The poor health of Indigenous Australians has been associated with experiences of racism in several previous studies [34,35].

This disadvantage is associated with both historical and contemporary racism, colonisation and oppression [34]. Data from a 2008 national survey indicate that $27 \%$ of Aboriginal and Torres Strait Islanders aged 15 years and over report experiencing racism in the past 12 months [36]. Previous studies exploring the health effects of racism for Indigenous Australians identify associations between self-reported racism and poor health, including: self assessed health status [37,38], physical $[39,40]$ and mental health outcomes $[34,35,39,41-43]$ as well as substance use $[34,44]$.

This paper focuses on interpersonal rather than institutional and/or systemic racism. It is acknowledged, however, that systemic racism is likely to have a stronger and more pervasive influence on health both directly and indirectly through upstream determinants (e.g. socioeconomic status). As well as focusing on interpersonal racism and health in an under-studied population, this paper adds to the scant literature examining factors through which racism may influence health. Research on such mediating factors and the causal pathways through which they operate can help identify "new options for coping with racism" [9]. We examined several variables as potential mediators of the relationship between racism and health, including: stress, optimism, social connections, lack of control, cultural identity and reactions/responses to interpersonal racism.

\section{Methods}

Data for this study was drawn from the Darwin Region Urban Indigenous Diabetes (DRUID) Study. Those eligible were adults aged 15 years or more who self-identified as Indigenous and who lived in a private dwelling in a defined geographical area in and around the city of Darwin, Australia [45]. DRUID was a cross-sectional study in which participants were recruited through community and family networks as well as local health centres/departments [45]. As such, the study sample is not necessarily representative of the eligible population. The study utilised questionnaires to assess health status, socio-demographics, and psychosocial and behavioural factors. Of the 164 respondents included in this analysis, $77 \%$ (126) completed the DRUID survey with the assistance of an interviewer while 23\% (38) self-administered the survey. The study was approved by the joint Human Research Ethics Committee of Menzies School of Health Research and Northern Territory Department of Health and Community Services.

\section{Measures}

The Measure of Indigenous Racism Experiences (MIRE) was used to assess racism [46]. Respondents were asked how often they were treated unfairly because they are Indigenous across nine mutually exclusive items covering experiences in employment, domestic, educational/ academic, recreational/leisure, law (enforcement), health care, government and non-government service provision (e.g. restaurants, bars, shops, banks) as well as general public settings (e.g. on the street, at shopping centres, sporting events, concerts, nightclubs etc.) [46]. Possible responses were: never (coded as 0), hardly ever (coded as 1 ), sometimes (coded as 2 ), often (coded as 3 ), very often (coded as 4) and 'not applicable'. The MIRE data examined in this paper appeared towards the end of the DRUID survey. Questions on health history, health behaviours, socioeconomic status, culture and identity, self-assessed health status and stressful experiences were asked prior to the MIRE questions, while questions on depression, lack of control, social support and optimism/pessimism were asked after the MIRE questions. 
As part of a larger stress checklist (described below), respondents were also asked if they or their family/ friends had experienced discrimination (not specifically attributed to race/ethnicity) that had affected them personally in the past 12 months ('discrimination-related stress'). Participants could respond that the event: was not experienced, had minimal/no effect, affected them somewhat, or affected them a great deal.

Age, sex, marital status and household composition (only Indigenous members or both Indigenous and nonIndigenous members) were assessed along with level of education, gross weekly household equivalised income using the modified OECD scale [47] and housing tenure. Five reactions and six responses to racism were also assessed as mediators. Reactions included: feeling ashamed, humiliated, anxious or fearful (labeled as 'ashamed'); feeling angry, annoyed or frustrated ('angry'); feeling amused, contemptuous or sorry for the person who did it ('amused'); feeling powerless, hopeless or depressed ('powerless'); and getting a headache, an upset stomach, tensing of your muscles, or a pounding heart ('somatic'). Responses included: ignoring, forgetting or accepting racism ('ignoring'); avoiding racism ('avoiding'); changing self or actions to prevent racism ('changing'); doing something about perpetrators or racist situations ('acting'); talking to family/friends or expressing racist experiences ('talking'); and keeping it to oneself ('withdrawing'). These items could be answered as: never, hardly ever, sometimes, often, or very often [46].

Stress over the past 12 months was assessed using a scale constructed de novo for the DRUID study. This included 10 items about acute stress (one-off, sudden or unexpected events including relationship breakup, death of partner/child, being fired, witness/target of violence, family member sent to jail, serious illness or accident/ injury as well as other unspecified events) and 20 items about chronic stress (regular or continuing events including trouble at work, school or relationships; problems with alcohol/drugs, gambling, money, mental/ emotional, health, employment, police or access to land/ country; abuse/violence, overcrowding; family in prison; pressure to fulfill cultural or family/carer responsibilities; worry about family; reliance on others for everyday needs as well as other unspecified events). Each of these items assessed stress experienced either personally or in relation to the respondent's family and close friends (i.e. vicarious stress). These 30 items were assessed using a four-point response scale (event not experienced, had minimal/no effect, affected me somewhat, or affected me a great deal).

Optimism was assessed using the Life Orientation Test-Revised (LOT-R) [48]. This scale includes six items assessing optimism in uncertain times, expectations that things will go wrong for the respondent, optimism about their future, whether they generally expect things to go their way, the degree that they count on good things happening to them and whether they expect more good than bad things to happen to them. Lack of control was assessed via four items (how much, in the past four weeks you felt a lack of control with: life in general; finances; personal life; and health) with responses: never/rarely, sometimes, often, or very often (d'Espaignet, Measey, \& Dal Grande, 2002).

Positive, negative and instrumental social connections were assessed using scales adapted from the Strong Heart Study [49]. Positive social connections included six items assessing the extent to which friends or relatives cared about, understood, or appreciated the respondent as well as to what degree he/she could rely upon, talk to, and relax around friends/relatives (not much, some and a lot). Negative social connections included five items assessing the degree to which friends/relatives made too many demands, argued with, criticised, let down or got on the nerves of the respondent (rarely/never, sometimes and often). Instrumental social connections were assessed with five items asking if there was someone the respondent could: go with to community/social events; borrow money from in an emergency; lend them a car or drive them somewhere if needed; ask to provide bail; and count on to check in on the respondent regularly (no; yes, one person or a few people; or yes, lots of people). As measures of cultural identity, participants were asked if they recognise a homeland/traditional country and whether they identify with a clan, tribe or language group.

Self-assessed health status was assessed using the Medical Outcomes Study Short Form-12 (SF-12) version 2 [50]. This self-report scale assesses health status via mental and physical component scores (MCS and PCS, respectively) and has established psychometric, clinical and predictive validity across a range of populations [51-54], including urban Indigenous Australians [55]. The SF-12 was scored using established methods [50].

\section{Analytical approach}

All analyses were conducted using Stata 10.1 for Windows (Stata Corporation, College Station, Texas: 2007). Of the 363 DRUID participants recruited during the period in which the MIRE was administered (Sept 2003Mar 2004), 312 completed at least some of the MIRE. Missing data across socio-demographic and psychosocial variables (see below) reduced this to a sample of 164 participants with complete data. The majority of those excluded were missing information on income $(n=65)$ and interpersonal racism $(\mathrm{n}=52)$, with $20-30$ also missing data for each of the psychosocial variables. Excluded participants were similar to those included across sociodemographic variables, with the exception that included 
participants had a higher level of education. Participants who were older, female and of higher socioeconomic status were over-represented in this study compared to the Darwin or total Australian Indigenous populations [45]. As recommended by Sterne et al. [56], we did not utilise multiple imputation methods because data were not missing at random (analyses not shown).

As the internal reliability of the nine racism items was good $(\alpha=0.83)$, responses were given values from zero (never) to four (very often) and summed, giving a potential range of $0-36$. As the internal reliabilities of the acute stress items $(\alpha=0.66)$, chronic stress items $(\alpha=$ $0.82)$ and total stress items combined $(\alpha=0.85)$ were adequate to good, weighted summary scores were also calculated for each of these constructs. The four responses were given numerical values from zero (no experience) to three (affected me a great deal) and summed across items giving a potential range of 0-30, 0-60 and 0-90 for acute, chronic and total stress, respectively. Positive $(\alpha=0.84)$, negative $(\alpha=0.75)$ and instrumental ( $\alpha=0.77)$ social connections were also summed and combined into composite variables. Both optimism $(\alpha=0.58)$ and lack of control $(\alpha=0.81)$ were coded as composite variables such that larger values represented higher levels of optimism and increased lack of control, respectively. The cultural identity items were coded dichotomously.

SF-12 MCS and PCS were examined as dependent variables in separate hierarchical regression models with racism as the independent variable. Even under various transformations, both the SF-12 MCS and PCS were significantly non-normal. As a result, these variables were dichotomised at the median $(0=$ lower quantile, $1=$ upper quantile) and were also coded separately as tertiles. As a form of sensitivity analysis, binary MCS and PCS variables were examined with logistic regression models while trinary-coded MCS and PCS variables were examined using both multinomial and ordinal models.

Age, sex and racism were included in the first step of the regression models, with additional socio-demographic variables (household composition, marital status, equivalised household income, housing tenure and level of education) added in the second step. Psychosocial variables (acute, chronic and total stress, optimism, lack of control, the three types of measures of social connections and the two cultural identity variables) were entered in the third step. The likelihood ratio test was used to assess significance for each step of the analysis. Variance inflation factors of less than two across all models indicated that multicollinearity was not present. Socio-demographic or psychosocial variables with significant main effects were examined as potential moderators in a model that included mental/physical health status, racism, the variable in question and its interaction with racism.

These same psychosocial variables plus responses/ reactions to racism were assessed separately as potential mediators of the association between racism (as the independent variable) and mental/physical health status (as the dependent variable). Given that mediated effects are unlikely to be normally distributed, bias-corrected non-parametric percentile confidence intervals were utilised. Because the forced symmetry of ordinary confidence intervals can result in estimation inaccuracies, bias-correct confidence intervals are adjusted to the percentile values of the sorted distribution of bootstrap estimates used for determining the bounds of the interval [57].

Bootstrapping with 5,000 replications was undertaken in order to provide increased statistical power [57]. As variables to be examined as potential mediators were non-normal (even under various transformations), they were dichotomised at the median and analysed using binary mediation with probit models $[58,59]$. Mediators found to be significant in models including only a single mediating variable between racism and mental/physical health status (adjusted for age, sex, household composition, marital status, equivalised household income, housing tenure and level of education) were then entered simultaneously in a multiple mediation model that adjusted for this same set of potential confounders. Separate models were run with both mental (SF-12 MCS = 1) and physical health (SF-12 PCS = 1) as the dependent variables.

In the results, the proportion of an association between the independent and the dependent variable accounted for by a specific mediator is expressed as a percentage. This proportion is calculated as variance in the dependent variable explained by the mediator (i.e. indirect effect) divided by sum of: (1) the variance in the dependent variable explained by the independent variable (i.e. direct effect); and (2) the variance in the dependent variable explained by the mediator (i.e. indirect effect/(indirect effect + direct effect)).

All models were also run using discrimination-related stress in place of interpersonal racism as the independent variable. Although this item assessed discrimination generally (including vicariously) rather than discrimination specifically attributed to race/ethnicity, duplicating analysis using this variable constitutes a form of sensitivity analysis that serves to assess the robustness of the findings relating to interpersonal racism (as the primary independent variable of interest). Consonant findings across these two variables indicate that spurious findings resulting from the multiple comparisons undertaken are not a concern (i.e. similar findings mitigate against Type I error). 


\section{Results}

Table 1 summarises participant characteristics. Participants ranged in age from 16-81 years (mean 39.7) and were predominantly female. The mean interpersonal racism score of 5.5 equates to approximately a quarter of respondents reporting no racism, half reporting 'hardly ever' experiencing racism and the remaining quarter reporting racism 'sometimes', 'often' or 'very often' on average across nine items. All participants included in the analysis reported experiencing racism in at least one setting. About a quarter of respondents reported racism in only one setting, a third in two settings, a quarter in three settings and a fifth in four or more settings. Respondents reported a range of reactions/responses to racism, such that no particular response was rare. Reported by over $80 \%$ of respondents, the most common reactions were feeling angry and amused and the most common responses were ignoring or talking about racism. Further details on the prevalence of reactions/responses to racism are detailed elsewhere [41].

Neither interpersonal racism nor discriminationrelated stress emerged as significant predictors SF-12 PCS in any regression models. Similarly, no significant findings were produced from mediation analysis with PCS as the dependent variable. Regression models with SF-12 MCS as the dependent variable and interpersonal racism as the independent variable are shown in Table 2. Interpersonal racism accounted for $8 \%$ of the variance in mental health (although included in model 1, analyses not shown indicate that age and sex accounted for none of this variance). Household composition, level of education, equivalised household income, housing tenure and marital status accounted for $7 \%$ of the variance in mental health. The psychosocial variables added in model 3 together explained another $29 \%$ of the variance. The likelihood ratio test was significant at each step of the analysis. Although negative social connections were significant in model 3 (Table 2, Odds Ratio: 0.82, CI 0.67$0.999)$, the interaction between racism and this variable was not significant.

Largely comparable results were produced in hierarchical regression models with discrimination-related stress (instead of interpersonal racism) as the independent variable (analyses not shown). One difference, however, was that lack of control emerged as a significant variable in the model that included all socio-demographic and psychosocial variables, with a significant interaction effect (i.e. moderation) between discrimination-related stress and this variable. Stratified analysis indicated that discrimination-related stress was only associated with poor mental health $(p=0.06)$ among participants
Table 1 Characteristics of DRUID participants ( $n=164$ for categorical variables)

\begin{tabular}{|c|c|c|}
\hline Categorical variables & Number* & $\%^{*}$ \\
\hline \multicolumn{3}{|l|}{ Sex } \\
\hline Male & 53 & 32 \\
\hline Female & 111 & 68 \\
\hline \multicolumn{3}{|l|}{ Age group (years) } \\
\hline $16-24$ & 26 & 16 \\
\hline $25-34$ & 36 & 22 \\
\hline $35-44$ & 42 & 26 \\
\hline $45-54$ & 38 & 23 \\
\hline $55-64$ & 15 & 9 \\
\hline $65+$ & 7 & 4 \\
\hline \multicolumn{3}{|l|}{ Marital status } \\
\hline Never Married & 38 & 23 \\
\hline Married/de facto & 88 & 54 \\
\hline Separated/divorced/widowed & 38 & 23 \\
\hline \multicolumn{3}{|l|}{$\begin{array}{l}\text { Gross weekly household equivalised income } \\
(\$ A U)\end{array}$} \\
\hline $1-199$ & 42 & 26 \\
\hline $200-499$ & 63 & 38 \\
\hline $500+$ & 59 & 36 \\
\hline \multicolumn{3}{|l|}{ Household tenure } \\
\hline Owned/being purchased & 82 & 50 \\
\hline Rented/other & 82 & 50 \\
\hline \multicolumn{3}{|l|}{ Household composition } \\
\hline All Indigenous members & 97 & 59 \\
\hline Indigenous and non-Indigenous members & 67 & 41 \\
\hline \multicolumn{3}{|l|}{ Level of education } \\
\hline Less than Year 10 & 34 & 21 \\
\hline Year 10/12 & 41 & 25 \\
\hline Non-degree qualifications & 65 & 40 \\
\hline Degree & 24 & 15 \\
\hline \multicolumn{3}{|l|}{ Identifies with a clan, tribe or language group } \\
\hline Yes & 118 & 72 \\
\hline No & 46 & 28 \\
\hline \multicolumn{3}{|l|}{ Recognises homeland/traditional country } \\
\hline Yes & 129 & 78 \\
\hline No & 35 & 22 \\
\hline \multicolumn{3}{|l|}{ Discrimination-related stress } \\
\hline Yes & 121 & 74 \\
\hline No & 43 & 26 \\
\hline$\underline{\text { Composite variables }}$ & Range & Mean (SD) \\
\hline Interpersonal racism & $0-24$ & $5.5(5.4)$ \\
\hline 10-item acute stress & $0-18$ & $4.8(4.4)$ \\
\hline 20-item chronic stress & $0-52$ & $11.9(8.6)$ \\
\hline 30-item total stress & $0-67$ & $15.8(11.9)$ \\
\hline Optimism & $12-30$ & $21.0(4.1)$ \\
\hline Lack of control & $0-12$ & $3.4(2.9)$ \\
\hline Positive social connections & $6-18$ & $15.3(2.9)$ \\
\hline Negative social connections & $5-13$ & $8.2(2.2)$ \\
\hline Instrumental social connections & $1-10$ & $6.2(2.0)$ \\
\hline
\end{tabular}


Table 1 Characteristics of DRUID participants $(n=164$ for categorical variables) (Continued)

\begin{tabular}{llc}
\hline Scored variables & Range & $\begin{array}{c}\text { Median } \\
\text { (SD) }\end{array}$ \\
SF-12 Mental Component Score & $19.7-65.8$ & $47.9(10.5)$ \\
SF-12 Physical Component Score & $18.1-66.1$ & $51.0(9.1)$ \\
& & \\
Individual MIRE items $(n=164)$ & Range & Mean (SD) \\
\hline Employment & $0-4$ & $0.76(1.08)$ \\
Domestic & $0-4$ & $0.44(0.85)$ \\
Educational/academic & $0-4$ & $0.56(0.97)$ \\
Recreational/leisure & $0-4$ & $0.49(0.83)$ \\
Law (enforcement) & $0-4$ & $0.48(0.89)$ \\
Health care & $0-3$ & $0.38(0.75)$ \\
Government service provision & & \\
Other service provision & $0-3$ & $0.51(0.89)$ \\
Public settings & $0-4$ & $0.93(1.05)$ \\
\hline
\end{tabular}

* Note: Percentages may not add to 100 due to rounding. SD (Standard Deviation) reporting a lack of control in life (i.e. those above the median score).

Multinomial and ordinal regression models also produced similar results with the exception that positive social connections emerged as an additional significant variable in the full multinomial and ordinal regression models with discrimination-related stress as the independent variable (analyses not shown).

Models including interpersonal racism along with a single mediating variable produced several significant findings (see Table 3). Feeling 'powerless' as a reaction to racism was a statistically significant mediator along with the three composite stress measures, lack of control and negative social connections. In each separate model, a single mediator accounted for $22 \%$ (negative social connections) to $71 \%$ (total stress) of the association between racism and mental health. Models with discrimination-related stress as the independent variable also identified feeling 'powerless' as a significant

Table 2 Hierarchical regression models with SF-12 MCS = 1 as the dependent variable\#

\begin{tabular}{|c|c|c|c|}
\hline & $\begin{array}{c}\text { Model } 1 \\
\text { OR (95\% Cl) }\end{array}$ & $\begin{array}{c}\text { Model } 2 \\
\text { OR }(95 \% \mathrm{CI})\end{array}$ & $\begin{array}{l}\text { Model } 3 \\
\text { OR }(95 \% \mathrm{Cl})\end{array}$ \\
\hline Interpersonal racism & $0.91(0.86-0.97)$ & $0.90(0.84-0.96)$ & $0.98(0.89-1.07)$ \\
\hline Age & $1.00(0.98-1.03)$ & $1.00(0.96-1.03)$ & $0.99(0.96-1.03)$ \\
\hline Female & $0.63(0.32-1.26)$ & $0.57(0.27-1.18)$ & $0.63(0.26-1.52)$ \\
\hline Mixed household & & $0.80(0.35-1.82)^{\prime}$ & $0.78(0.29-2.10)$ \\
\hline \multicolumn{4}{|l|}{ Education } \\
\hline Less than Year 10 & & 1.00 & 1.00 \\
\hline Year 10/12 & & $0.93(0.31-2.74)$ & $0.81(0.23-2.80)$ \\
\hline Non-degree & & $0.66(0.23-1.86)$ & $1.00(0.29-3.45)$ \\
\hline Degree & & $1.09(0.30-3.95)$ & $1.47(0.31-6.95)$ \\
\hline \multicolumn{4}{|l|}{ Household equivalised income } \\
\hline "\$1"-199 & & 1.00 & 1.00 \\
\hline$\$ 200-499$ & & $1.25(0.52-3.04)$ & $0.57(0.20-1.67)$ \\
\hline$\$ 500+$ & & $1.97(0.72-5.39)$ & $0.76(0.22-2.67)$ \\
\hline Own/purchasing home & & $1.48(0.71-3.10)$ & $1.83(0.78-4.31)$ \\
\hline \multicolumn{4}{|l|}{ Marital status } \\
\hline Never married & & 1.00 & 1.00 \\
\hline Married/defacto & & $1.46(0.53-4.01)$ & $1.96(0.57-6.77)$ \\
\hline Separated etc. & & $0.74(0.22-2.52)$ & $0.85(0.21-3.48)$ \\
\hline Acute stress & & & $0.91(0.82-1.02)$ \\
\hline Chronic stress & & & $0.97(0.91-1.04)$ \\
\hline Optimism & & & $1.05(0.95-1.17)$ \\
\hline Lack of control & & & $0.85(0.71-1.00)$ \\
\hline Negative social connections & & & $\mathbf{0 . 8 2}(0.67-1.00)$ \\
\hline Positive social connections & & & $1.13(0.95-1.33)$ \\
\hline Instrumental social connections & & & $1.04(0.83-1.29)$ \\
\hline Identifies with clan/tribal/language & & & $0.83(0.31-2.26)$ \\
\hline Recognises homeland country & & & $0.56(0.17-1.77)$ \\
\hline Constant & $3.27(0.73-14.68)$ & $3.40(0.46-25.19)$ & $3.77(0.05-273.5)$ \\
\hline McKelvey-Zavoina R-squared [60] & 0.084 & 0.154 & 0.440 \\
\hline
\end{tabular}

\# SF-12 MCS is split at the median with the lower quantile (poorer mental health) coded as 0 and the upper quantile (better mental health) coded as 1 . Other variables are continuous except where indicated 
Table 3 Factors significantly mediating the association between interpersonal racism and mental health (single mediation models)

\begin{tabular}{lllll}
\hline Mediator & $\boldsymbol{\beta}$ coefficient & Bias-corrected lower Cl & Bias-corrected upper Cl & \% of effect mediated \\
\hline Total stress & -0.265 & -0.416 & -0.097 & 71.4 \\
Chronic stress & -0.197 & -0.343 & -0.058 & 56.8 \\
Lack of control & -0.139 & -0.247 & -0.045 & 40.1 \\
Powerless & -0.136 & -0.250 & -0.043 & 39.2 \\
Acute stress & -0.126 & -0.231 & -0.040 & 36.6 \\
Negative social connections & -0.074 & -0.171 & -0.001 & 22.2 \\
\hline
\end{tabular}

mediator along with somatic reactions to racism and the three composite stress measures (see Table 4).

In the multiple mediation model with interpersonal racism as the independent variable, acute stress and lack of control remained as significant mediators after simultaneous adjustment for other mediators (see Table 5). All the mediating variables in this model (powerless, acute and chronic stress, lack of control and negative social connections) together accounted for $94 \%$ of the association between racism and mental health. Feeling 'powerless' as well as acute and chronic stress emerged as significant mediators in the multiple mediation model with discrimination-related stress as the independent variable (see Table 6). All the mediating variables in this model (powerless, somatic reaction, acute and chronic stress) together accounted for $75 \%$ of the association between discrimination-related stress and mental health.

\section{Discussion}

This study found that after adjustment for socio-demographic factors, interpersonal racism is associated with mental but not physical health in a non-U.S. indigenous population. Stress, lack of control and feeling powerless as a reaction to racism emerged in multiple mediation models as significant mediators of the relationship between racism and general mental health.

To our knowledge, this is only the third study to show that racism is associated with general mental health among an indigenous population [35,38]. A study among 153 Indigenous Australians found that experiencing regular racism was associated with poor mental health (MCS SF-12) after adjusting for gender, age, education, employment and financial stress, but no association with physical health (PCS SF-12) was evident [35]. Some previous studies have similarly found that racism is only significantly associated with the mental but not physical health scale of the SF-12/36 [35,61-64] while others identified an association with the physical health scale [39,65-68]. Although the aetiology behind such differences is not yet understood, stronger associations between racism and mental (as opposed to physical) health have been noted worldwide [3-5]. As suggested in recent reviews, it is likely that racism impacts primarily on mental health, with physical health effects mediated through mental processes $[8,9]$.

To our knowledge, no previous study has examined the factors included in this study as mediators/moderators of the relationship between racism and physical health. Lack of control is now well-established as a determinant of morbidity and mortality $[69,70]$. Only two previous studies have shown that lack of control acts as a mediator of the association between racism and mental health (see below) while control beliefs failed to emerge as a mediator between racism and depression in another study [71]. In a study involving 108 Arab-Americans, lack of control completely mediated the association between racism and selfesteem, and partially mediated the association between racism and psychological distress [72]. Similarly, mastery (i.e. the opposite of lack of control) mediated the relationship between racism and psychological distress among 485 African-American, Native-American and Asian-Americans [73]. Racism may lead to lack of control by creating unfair and unpredictable demands as well as attenuating rewards resulting from effort, with one study finding that increased reporting of racism

Table 4 Factors significantly mediating the association between discrimination-related stress and mental health (single mediation models)

\begin{tabular}{|c|c|c|c|c|}
\hline Mediator & $\beta$ coefficient & Bias-corrected lower $\mathrm{Cl}$ & Bias-corrected upper $\mathrm{Cl}$ & $\%$ of effect mediated \\
\hline Total stress & -0.188 & -0.301 & -0.076 & 92.4 \\
\hline Powerless & -0.111 & -0.214 & -0.024 & 74.8 \\
\hline Chronic stress & -0.134 & -0.238 & -0.044 & 85.9 \\
\hline Acute stress & -0.140 & -0.244 & -0.045 & 85.8 \\
\hline Somatic reaction & -0.071 & -0.170 & -0.004 & 48.7 \\
\hline
\end{tabular}


Table 5 Factors mediating the association between interpersonal racism and mental health (multiple mediation model)

\begin{tabular}{lllll}
\hline Mediator & $\boldsymbol{\beta}$ coefficient & Bias-corrected lower Cl & Bias-corrected upper Cl & \% of effect mediated \\
\hline Lack of control & -0.088 & -0.200 & -0.011 & 22.1 \\
Acute stress & -0.086 & -0.188 & -0.012 & 21.5 \\
Chronic stress & -0.095 & -0.229 & 0.043 & 23.8 \\
Powerless & -0.086 & -0.194 & 0.121 & 21.5 \\
Negative social connections & -0.021 & -0.100 & 0.047 & 5.4 \\
Total indirect effect & -0.377 & -0.538 & -0.182 & 94.3 \\
\hline
\end{tabular}

among Latino students was associated with lack of control [74]. In one previous study of racism and health among Indigenous Australians, mastery failed to emerge as a significant mediator [40]. To our knowledge, this is the first study to suggest that lack of control may act as an effect modifier between discrimination and poor mental health, with discrimination only affecting only those low in control.

Eleven studies have examined social support, connections or capital as a mediator/moderator of the association between racism and mental health, with some evidence that it ameliorates the detrimental effect of racism on health $[5,75]$. This study, however, is the first to examine the role of negative social connections, finding it to be a significant mediator (but not moderator) of the relationship between racism and poor health when considered alone in a single variable mediator model.

It is possible that racism perpetrated by friends or relatives may take the form of demands, arguments, criticism, being let down or annoyance. Alternatively, or in addition, racism-related stress may precipitate negative social connections or reduce the capacity of individuals to tolerate social connections (hence increasing the reporting of negative connections). This latter possibility is supported by a study which found racism to be associated with increased reporting of routine social interactions as harassing, exclusionary, and unfair [76]. The failure of this mediator to emerge in the multiple mediation model suggests that it may act as a second-order mediator in a causal pathway with stress as the primary mediator.
Although two previous studies have found that improved mental health outcomes are associated with active rather than passive coping responses to racism $[77,78]$, none of the six responses to racism mediated the association between racism and mental health in the DRUID study. However, powerlessness as a reaction to racism was found to be a significant mediator. This finding is particularly disturbing given that among a nationally representative group of Indigenous Australians, almost a third (28\%) reported feeling powerlessness as a reaction to racism [34]. Somatic reaction was significant in single variable mediation models but was no longer so in the multiple mediation model. Although no previous research has examined reactions as mediators of the relationship between racism and ill-health, a study involving 183 Indigenous Australians found that racism which evoked an emotional/physical response was related to poor general health [39].

A previous study involving 215 multiethnic college students found that optimism was inversely associated with depression in a model that also included perceived racism [79]. However, this construct failed to emerge as a statistically significant mediator between racism and mental health in the DRUID study. Given that no other studies have specifically focused on optimism as a mediator, it is not yet clear how this construct may contribute to the aetiology of racism as a determinant of health.

Reviews in this field suggest that stress acts as a mediator between racism and poor health [3-5]. However, only a few studies have examined such a role, with stress acting as mediator between racism and: smoking

Table 6 Factors mediating the association between discrimination-related stress and mental health (multiple mediation model)

\begin{tabular}{lllll}
\hline Mediator & $\boldsymbol{\beta}$ coefficient* & Bias-corrected lower $\mathbf{C l}$ & Bias-corrected upper $\mathrm{Cl}$ & \% of effect mediated \\
\hline Powerless & -0.074 & -0.175 & -0.007 & 19.9 \\
Chronic stress & -0.090 & -0.190 & -0.020 & 24.3 \\
Acute stress & -0.095 & -0.194 & -0.015 & 25.8 \\
Somatic reaction & -0.017 & -0.110 & 0.054 & 4.7 \\
Total indirect effect & -0.276 & -0.414 & -0.129 & 74.7 \\
\hline
\end{tabular}


[21], depression/anxiety [80,81], hypertension [82] and psychological well-being [75] while failing to emerge as a mediator between racism and depression [83]. Both acute and chronic stress emerged as important mediators in this study, remaining significant in multiple mediation models (with the exception of chronic stress in the interpersonal racism model). This supports the view that racism acts (at least in part) as a form of stress that, in turn, leads to both physical and mental ill-health through various psychological and physical consequences (e.g. allostatic load) [84].

Although four studies have found that ethnic identity buffers racism-related stress $[75,80,85,86]$, a recent review of 12 studies notes that identity is not sufficient to completely ameliorate the effects of racism on health [87]. It is not clear why the two aspects of cultural identity assessed in this study failed to emerge as either significant mediators or moderators of the association between racism and mental health.

Results from models with interpersonal racism and discrimination-related stress were largely consistent, providing confidence that findings were not spurious. There were, however, some differences in findings across these two independent variables. In particular, discrimination-related stress was only associated with poor mental health among participants reporting a lack of control in life while no moderation was detected for interpersonal racism. While four significant mediators emerged in common across these two variables in single-mediation models, lack of control and negative social connections mediated only in models with interpersonal racism while somatic reactions mediated only in the model with discrimination-related stress as the independent variable. In multiple mediation models, acute stress was significant in both models. Lack of control was only significant in interpersonal racism model while powerlessness and chronic stress were significant in the discrimination-related stress model.

Variations in findings across the two measures of exposure may be related to the fact that discriminationrelated stress assessed experiences not specifically attributed to race/ethnicity. Previous studies have found that association with health can vary across different measures of discrimination [88-90]. Further work is required to understand the nature and implications of these differential associations. Differences may also be due to the fact that discrimination-related stress also included assessment of vicarious as well as personal experiences of racism (i.e. racism experienced by family/friends). Although research on vicarious racism is very limited [3-5], there is some evidence of its detrimental effects on health and wellbeing [40].

The robustness of study findings is supported by broadly similar findings for both interpersonal racism and discrimination-related stress. Nonetheless, there are several study limitations to note. First, in terms of measurement, it is evident that racism can go unnoticed when it does occur and be perceived when it is not 'objectively' present (i.e. an avoidable and unfair inequality of resources, opportunity or benefit has not, in fact occurred). However, as with stress, perceived racism may act as a determinant of health regardless of its objective veracity [3-5].

The MIRE captures only those experiences of racism that respondents perceive and are willing to report. There is evidence that respondents are more likely to underestimate than overestimate experiences of racism [91-94]. This is due to a combination of factors, including the poorly understood (and largely invisible) nature of systemic racism, the protective effects that may accrue from not attributing experiences to racism [95], and the negative social repercussions of labelling an experience as racism [94].

Although 32 longitudinal studies suggest that the primary direction of causation is from racism to ill-health rather than ill-health leading to increased reporting of racism [3-5,96-98], the latter cannot be ruled out in this cross-sectional study.

Failure to identify any significant moderators may have been due to the low power of moderation tests [99] combined with a relatively small sample size. Similarly, low power due to both the small sample size and the need to dichotomise mediators may have precluded identification of weaker mediation effects [100].

With figures ranging from $0.60-0.80$ in the literature $[101,102]$, there is no established cut-off for satisfactory reliability as measured by Cronbach's alpha. Nonetheless, it is clear that two of the composite measures in this study had low to moderate internal consistencies (acute stress: $\alpha=0.66$ and optimism: $\alpha=0.58$ ). As such, these scales may have not have tapped into their respective underlying constructs with sufficient accuracy. While the optimism scale (LOT-R) has well established internal consistency [103], the acute stress scale is novel to DRUID and its psychometric properties should be examined in further research.

\section{Conclusions}

This study highlights the complex pathways leading from racism to mental ill-health and elucidates several new avenues for further research and practice. It is notable that the mediating variables examined here together accounted for $75 \%$ and $94 \%$ of the association between discrimination-related stress and interpersonal racism and mental health, respectively. This indicates the importance of understanding the aetiology of racism as a determinant of health. In addition to reinforcing the clear need to reduce the incidence of racism [104], 
such an improved understanding may help direct efforts to combat the effects of racism. In particular, this study highlights the importance of reducing consequent stress, enhancing general levels of mastery, and minimising negative social connections in order to ameliorate the negative consequences of racism.

\section{Acknowledgements}

The authors gratefully acknowledge the support of DRUID study participants, study staff, members of the Indigenous Steering Group, and partner organisations. The DRUID Study was funded by the National Health and Medical Research Council (NHMRC Project Grant \#236207), with additional support from the Australian Government Department of Employment and Workplace Relations, the Clive and Vera Ramaciotti Foundation, the Vincent Fairfax Family Foundation, the International Diabetes Institute (AusDiab Partnership), and Bayer HealthCare. The DRUID Study is an in-kind project of the Cooperative Research Centre for Aboriginal Health (CRCAH). Ms Hannah Reich provided research assistance in the drafting of this manuscript. The first author was supported by a University of Melbourne McKenzie fellowship. The second author was supported by an NHMRC Career Development Award (\#283310) and an NHMRC Research Fellowship (\#545200).

\section{Author details}

${ }^{1}$ McCaughey Centre, Melbourne School of Population Health, University of Melbourne, Melbourne, Australia. ${ }^{2}$ Menzies School of Health Research Charles Darwin University, Darwin, Australia and School of Population Health, University of Melbourne, Melbourne, Australia.

\section{Authors' contributions}

YP was involved in designing the study, conducted the data analysis and wrote the manuscript. JC was involved in the design and coordination of the project, participated in data collection, advised on data analysis and edited the manuscript. All authors read and approved the final manuscript.

\section{Competing interests}

The authors declare that they have no competing interests.

Received: 2 August 2011 Accepted: 14 February 2012 Published: 14 February 2012

\section{References}

1. Berman G, Paradies Y: Racism, disadvantage and multiculturalism: towards effective anti-racist praxis. Ethnic \& Racial Studies 2010, 33:214-232.

2. Krieger N: Embodying inequality: a review of concepts, measures, and methods for studying health consequences of discrimination. Int I Health Serv 1999, 29:295-352.

3. Paradies $Y$ : A systematic review of empirical research on self-reported racism and health. Int J Epidemiol 2006, 35:888-901.

4. Williams DR, Mohammed SA: Discrimination and racial disparities in health: evidence and needed research. J Behav Med 2009, 32:20-47.

5. Pascoe EA, Richman LS: Perceived Discrimination and Health: A MetaAnalytic Review. Psychol Bull 2009, 135:531-554.

6. Sanders-Phillips K: Racial discrimination: a continuum of violence exposure for children of color. Clin Child Fam Psychol Rev 2009, 12:174-195.

7. Paradies Y, Forrest J, Dunn K, Pedersen A, Webster K, Mansouri F: More than Tolerance: Racism and the Health of Young Australians. Youth Identity and Migration: Culture, Values and Social Connectedness Altona, Victoria.: Common Ground Publishing; 2009, 207-226.

8. Harrell CP, Burford TI, Cage BN, McNair Nelson T, Shearon S, Thompson A, Green S: Multiple Pathways Linking Racism to Health Outcomes. Du Bois Review 2011, 8:143-157.

9. Brondolo E, Brady N, Libby D, Pencille M: Racism as a Psychosocial Stressor. In Handbook of Stress Science. Edited by: Contrada R. New York: Springer; 2010:.
10. Brondolo E, Pencille M, Schoenthaler A, Ogedegbe G: Racism and Hypertension: A Review of the Empirical Evidence and Implications for Clinical Practice. American Journal of Hypertension 2011, online march 2011.

11. De Santis AS, Adam EK, Doane LD, Mineka S, Zinbarg RE, Craske MG: Racial/ ethnic differences in cortisol diurnal rhythms in a community sample of adolescents. J Adolesc Health 2007, 41:3-13.

12. Richman $L S$, Jonassaint $C$ : The effects of race-related stress on cortisol reactivity in the laboratory: implications of the Duke lacrosse scandal. Annals of Behav Med 2008, 35:105-110.

13. Tull ES, Sheu YT, Butler C, Cornelious K: Relationships between perceived stress, coping behavior and cortisol secretion in women with high and low levels of internalized racism. J National Med Assoc 2005, 97:206-212.

14. Thomas KS, Bardwell WA, Ancoli-Israel S, Dimsdale JE: The toll of ethnic discrimination on sleep architecture and fatigue. Health Psychol 2006, 25:635-642.

15. Lewis TT, Troxel WM, Kravitz HM, Bromberger JT, Matthews KA, Hall M: Do chronic experiences of everyday discrimination keep women awake at night? The Study of Women's Health Across the Nation (SWAN) sleep study. Book Do chronic experiences of everyday discrimination keep women awake at night? The Study of Women's Health Across the Nation (SWAN) sleep study 2011, (Editor ed.^eds.). City.

16. Lewis TT, Kravitz HM, Janssen I, Powell LH: Self-reported Experiences of Discrimination and Visceral Fat in Middle-aged African-American and Caucasian Women. Am J Epidemiol 2011, 2011:1-9, Advance Access published February 25.

17. Hunte HER: Association Between Perceived Interpersonal Everyday Discrimination and Waist Circumference Over a 9-Year Period in the Midlife Development in the United States Cohort Study. Am J Epidemiol 2011, 2011:1-8, Advance Access published February 25.

18. Shelton RC, Puleo E, Bennett GG, McNeill LH, Sorensen G, Emmons KM: The association between racial and gender discrimination and body mass index among residents living in lower-income housing. Ethn Dis 2009, 19:251-257.

19. Bennett GG, Wolin KY, Robinson EL, Fowler S, Edwards CL: Perceived racial/ ethnic harassment and tobacco use among African American young adults. Am J Public Health 2005, 95:238-240.

20. Chae DH, Takeuchi DT, Barbeau EM, Bennett GG, Lindsey J, Krieger N: Unfair Treatment, Racial/Ethnic Discrimination, Ethnic Identification, and Smoking Among Asian Americans in the National Latino and Asian American Study. Am J Public Health 2008, 98:485-492.

21. Guthrie BJ, Young AM, Williams DR, Boyd CJ, Kintner ER: African American girls' smoking habits and day-to-day experiences with racial discrimination. Nurs Res 2002, 51:183-189.

22. Landrine $H$, Klonoff EA: Racial discrimination and cigarette smoking among Blacks: Findings from two studies. Ethn Dis 2000, 10:195-202.

23. Okamoto J, Ritt-Olson A, Soto D, Baezconde-Garbanati L, Unger JB: Perceived Discrimination and Substance Use among Latino Adolescents. Am J Heal Beh 2009, 33:718-727.

24. Choi Y, Harachi TW, Gillmore MR, Catalano RF: Are multiracial adolescents at greater risk? Comparisons of rates, patterns, and correlates of substance use and violence between monoracial and multiracial adolescents. Am J Orthopsychiatr 2006, 76:86-97.

25. Gee GC, Delva J, Takeuchi D: Relationships Between Self-Reported Unfair Treatment and Prescription Medication Use, Illicit Drug Use, and Alcohol Dependence Among Filipino Americans. Am J Public Health 2007, 97:933-940.

26. Gibbons FX, Gerrard M, Cleveland MJ, Wills TA, Brody G: Perceived Discrimination and Substance Use in African American Parents and Their Children: A Panel Study. J PersSoc Psychol 2004, 86:517-529.

27. Gibbons FX, Yeh HC, Gerrard M, Cleveland MJ, Cutrona C, Simons RL, Brody $\mathrm{GH}$ : Early experience with racial discrimination and conduct disorder as predictors of subsequent drug use: A critical period hypothesis. Drug Alcohol Depend 2007, 88:S27-S37.

28. Otiniano AD, Gee GC, Ford CL, Iguchi M, Friedman S: Discrimination and substance use among Latina/os: differences by gender. Book Discrimination and substance use among Latina/os: differences by gender 2011, (Editor ed.^eds.). City.

29. Steffen PR, Bowden M: Sleep disturbance mediates the relationship between perceived racism and depressive symptoms. Ethn Dis 2006, 16:16-21. 
30. Chen C, Lin K: Health consequences of illegal drug use. Curr Opin Psychiatry 2009, 22:287-292.

31. Jane-Llopis E, Matytsina I: Mental health and alcohol, drugs and tobacco: a review of the comorbidity between mental disorders and the use of alcohol, tobacco and illicit drugs. Drug Alcohol Rev 2006, 25:515-536.

32. Paradies Y, Williams DR, Heggenhougen K, Quah S: Racism and Health. In Encyclopedia of Public Health. Volume 5. San Diego: Academic Press; 2008:474-483.

33. Steering Committee for the Review of Government Service P: Overcoming Indigenous Disadvantage: Key Indicators 2009. Book Overcoming Indigenous Disadvantage: Key Indicators 2009 City: Productivity Commission; 2009, (Editor ed.^eds.).

34. Paradies $Y$, Harris $R$, Anderson I: The Impact of Racism on Indigenous Health in Australia and Aotearoa: Towards a Research Agenda. Book The Impact of Racism on Indigenous Health in Australia and Aotearoa: Towards a Research Agenda City: Cooperative Research Centre for Aboriginal Health; 2008, (Editor ed.^eds.).

35. Gallaher G, Ziersch AM, Baum F, Bentley M, Palmer C, Edmondson W, Winslow L: In our own backyard: urban health inequities and Aboriginal experiences of neighbourhood life, social capital and racism. Book In our own backyard: urban health inequities and Aboriginal experiences of neighbourhood life, social capital and racism City: Flinders University; 2009, (Editor ed. $\wedge$ eds.).

36. 4704.0 - The Health and Welfare of Australia's Aboriginal and Torres Strait Islander Peoples. [http://www.abs.gov.au/AUSSTATS/abs@.nsf/lookup/ 4704.0Chapter4500ct+2010].

37. Paradies $Y$, Cunningham J: Experiences of racism among urban Indigenous Australians: Findings from the DRUID study. Ethnic \& Racial Studies 2010, 32:548-573.

38. Priest N, Paradies Y, Gunthorpe W, Cairney S, Sayers S: Racism as a determinant of social and emotional wellbeing for Aboriginal Australian youth. Med J Australia 2011, 194:546-550.

39. Larson A, Gilles M, Howard PJ, Coffin J: It's enough to make you sick: the impact of racism on the health of Aboriginal Australians. AustNZJPublic Health 2007, 31:322-329.

40. Priest N, Paradies Y, Stevens M, Bailie R: Exploring relationships between racism, housing and child illness in remote Aboriginal communities. J Epidemiol Commun Heal 2012.

41. Paradies $Y$, Cunningham J: Experiences of racism among urban Indigenous Australians: Findings from the DRUID study. Ethnic \& Racial Studies 2009, 32:548-573.

42. Priest N, Paradies $Y$, Stevens M, Bailie R: Exploring relationships between racism, housing and child illness in remote Aboriginal communities. $J$ Epidemiol Commun Heal

43. Paradies Y, Cunningham J: The DRUID study: Exploring mediating pathways between racism and depressive symptoms among Indigenous Australians. Social Psychiatry and Psychiatric Epidemiol

44. Zubrick SR, Silburn SR, Lawrence DM, Mitrou FG, Dalby RB, Blair EM, Griffin J, Milroy H, De Maio JA, Cox A, Li J: Western Australian Aboriginal Child Health Survey: The Social and Emotional Wellbeing of Aboriginal Children and Young People. Book Western Australian Aboriginal Child Health Survey: The Social and Emotional Wellbeing of Aboriginal Children and Young People City: Curtin University of Technology and Telethon Institute for Child Health Research; 2005, (Editor ed.^eds.)

45. Cunningham J, O'Dea K, Dunbar T, Weeramanthri T, Zimmet P, Shaw J: Study Protocol - Diabetes and related conditions in urban Indigenous people in the Darwin, Australia region: aims, methods and participation in the DRUID Study. BMC Public Health 2006, 6(8).

46. Paradies Y, Cunningham J: Development and Validation of the Measure of Indigenous Racism Experiences (MIRE). International Journal for Equity in Health 2008, 7(9).

47. Hagenaars AK, Zaidi MA: Poverty Statistics in the Late 1980s: Research Based on Micro-data. Book Poverty Statistics in the Late 1980s: Research Based on Micro-data City: Office for Official Publications of the European Communities; 1994, (Editor ed.^eds.).

48. Scheier MF, Carver CS, Bridges MW: Distinguishing optimism from neuroticism (and trait anxiety, self-mastery, and self-esteem): A reevaluation of the Life Orientation test. J PersSoc Psychol 1994, 67:1063-1078.

49. Manson S, Beals J: Indian Services Utilization and Psychiatric Epidemiology Risk and Protective Factors Project: Survey Instrument and
Coding Guide. Book Indian Services Utilization and Psychiatric Epidemiology Risk and Protective Factors Project: Survey Instrument and Coding Guide City: University of Colorado, Denver; 1995, (Editor ed.^eds.).

50. Ware JE, Kosinski M, Turner-Bowker DM, Gandek B: How to Score Version 2 of the Sf-12 Health Survey (With a Supplement Documenting Version 1). Book How to Score Version 2 of the Sf-12 Health Survey (With a Supplement Documenting Version 1) City: QualityMetric Incorporated; 2002, (Editor ed. ^eds.).

51. Operario D, Adler NE, Williams DR: Subjective Social Status: Reliability and Predictive Utility for Global Health. Psychol Heal 2004, 19:237-246.

52. DeSalvo KB, Bloser N, Reynolds K, He J, Muntner P: Mortality prediction with a single general self-rated health question. J Gen Intern Med 2006, 21:267-275.

53. Idler EL, Benyamini Y: Self-rated health and mortality; A review of twentyseven community studies. J Health SocBehav 1997, 38:21-37.

54. Gill SC, Butterworth P, Rodgers B, Mackinnon A: Validity of the mental health component scale of the 12-item Short-Form Health Survey (MCS12) as measure of common mental disorders in the general population. Psychiatry Research 2007, 152:63-71.

55. Sibthorpe B, Anderson I, Cunningham J: Self-assessed health status among Indigenous Australians: How valid is a global question? Am J Public Health 2001, 91:1660-1663.

56. Sterne JA, White IR, Carlin JB, Spratt M, Royston P, Kenward MG, Wood AM, Carpenter JR: Multiple imputation for missing data in epidemiological and clinical research: potential and pitfalls. British Med J 2009, 338:b2393.

57. Preacher KJ, Hayes AF: Asymptotic and resampling strategies for assessing and comparing indirect effects in multiple mediator models. Behav Res Methods 2008, 40:879-891.

58. Pituch KA, Stapleton LM: The Performance of Methods to Test UpperLevel Mediation in the Presence of Nonnormal Data. Multivar Behav Res 2008, 43:237-267.

59. Ender P: How can I perform mediation with binary variables? UCLA. Academic Technology Services, Statistical Consulting Group; 2010.

60. DeMaris A: Explained Variance in Logistic Regression: A Monte Carlo Study of Proposed Measures. Sociol Methods Res 2002, 31:27-74.

61. Caputo RK: The Effects of Socioeconomic Status, Perceived Discrimination and Mastery on Health Status in a Youth Cohort. Social Work in Health Care 2003, 37:17-42.

62. Franzini L, Fernandez-Esquer ME: Socioeconomic, cultural, and personal influences on health outcomes in low income Mexican-origin individuals in Texas. SocSciMed 2004, 59:1629-1646.

63. Gee GC: A Multilevel Analysis of the Relationship Between Institutional and Individual Racial Discrimination and Health Status. Am J Public Health 2002, 92:615-623.

64. Sellers SL, Bonham V, Neighbors HW, Amell JW: Effects of Racial Discrimination and Health Behaviors on Mental and Physical Health of Middle-Class African American Men. Health Educ Behav 2006.

65. Borrell LN, Kiefe Cl, Williams DR, Diez-Roux AV, Gordon-Larsen P: Selfreported health, perceived racial discrimination, and skin color in African Americans in the CARDIA study. SocSciMed 2006, 63:1415-1427.

66. Harris R, Tobias M, Jeffreys M, Waldergrave K, Karlsen S, Nazroo J: Racism and health: The relationship between experience of racial discrimination and health in New Zealand. SocSciMed 2006, 63:1428-1441.

67. Piette JD, Bibbins-Domingo K, Schillinger D: Health care discrimination, processes of care, and diabetes patients' health status. Patient Educ Couns 2006, 60:41-48.

68. Sohn L, Harada ND: Effects of Racial/Ethnic Discrimination on the Health Status of Minority Veterans. Military Medecine 2008, 173:331-338.

69. Chandola T, Kuper H, Singh-Manoux A, Bartley M, Marmot M: The effect of control at home on CHD events in the Whitehall II study: Gender differences in psychosocial domestic pathways to social inequalities in CHD. SocSciMed 2004, 58:1501-1509.

70. Griffin J, Fuhrer R, Stansfeld S, Marmot M: The importance of low control at work and home on depression and anxiety: Do these effects vary by gender and social class? Social Sci Med 2002, 54:783-798.

71. Deardorff J, Gonzales NA, Sandler IN: Control beliefs as a mediator of the relation between stress and depressive symptoms among inner-city adolescents. J Abnormal Child Psychol 2003, 31:205-217.

72. Moradi B, Hasan NT: Arab American Persons' Reported Experiences of Discrimination and Mental Health: The Mediating Role of Personal Control. J Couns Psychol 2004, 51:418-428. 
73. Rodriguez MS: Effects of perceived discrimination on mental health: Exploring intervening relationships. Kent State University 2004

74. Shorey HS, Cowan G, Sullivan MP: Predicting perceptions of discrimination among Hispanics and Anglos. Hisp J Behav Sci 2002, 24:3-19.

75. Heim D, Hunter SC, Jones R: Perceived Discrimination, Identification, Social Capital, and Well-Being: Relationships With Physical Health and Psychological Distress in a U.K. Minority Ethnic Community Sample. J Cross Cultural Psychol.

76. Broudy R, Brondolo E, Coakley V, Brady N, Cassells A, Tobin JN, Sweeney M: Perceived Ethnic Discrimination in Relation to Daily Moods and Negative Social Interactions. J BehavMed 2007, 30:31-43.

77. Liang CTH, Alvarez AN, Juang L, Liang MX: The Role of Coping in the Relationship Between Perceived Racism and Racism-Related Stress for Asian Americans: Gender Differences. J Couns Psychol 2007, 54:132-141.

78. Alvarez AN, Juang LP: Filipino Americans and Racism: A Multiple Mediation Model of Coping. J Couns Psychol 2010, 57:167-178.

79. Ong AD, Edwards LM: Positive Affect and Adjustment to Perceived Racism. J Soc Clin Psychol 2008, 27:105-126.

80. Sellers $\mathrm{R}$, Caldwell CH, Schmeelk-Cone KH, Zinnerman MA: Racial identity, racial discrimination, perceived stress, and psychological distress among African American young adults. J Heal Soc Behav 2003, 44:302-317.

81. Ong AD, Fuller-Rowell T, Burrow AL: Racial discrimination and the stress process. J Pers Soc Psychol 2009, 96:1259-1271.

82. Din-Dzietham R, Nembhard WN, Collins R, Davis SK: Perceived stress following race-based discrimination at work is associated with hypertension in African-Americans. The metro Atlanta heart disease study, 1999-2001. SocSciMed 2004, 58:449-461.

83. Todorova I, Falcon LM, Lincoln AK, Price LL: Perceived discrimination, psychological distress and health. Sociol Heal IIIn 2010, 32:843-861.

84. Paradies Y: Psychosocial Stress and Health: A Conceptual Review. Int J Psychol Res 2010, 5, article10.

85. Mossakowski KN: Coping with perceived discrimination: Does ethnic identity protect mental health? J Heal Soc Behav 2003, 44:318-331.

86. Banks KH, Kohn-Wood L: The influence of racial identity profiles on the relationship between racial discrimination and depressive symptoms. $J$ Black Psychol 2007, 33:331-354.

87. Brondolo E, Brady VerHalen NB, Pencille M, Beatty D, Contrada RJ: Coping with racism: a selective review of the literature and a theoretical and methodological critique. J Behav Med 2009, 32:64-84.

88. Yoo HC, Gee GC, Takeuchi D: Discrimination and health among Asian American immigrants: Disentangling racial from language discrimination. SocSciMed 2009, 68:726-732.

89. Gee GC, Ro A, Gavin A, Takeuchi DT: Disentangling the Effects of Racial and Weight Discrimination on Body Mass Index and Obesity Among Asian Americans. Am J Public Health 2008, 98:493-500.

90. Noh S, Kaspar V, Wickrama KA: Overt and Subtle Racial Discrimination and Mental Health: Preliminary Findings for Korean Immigrants. Am J Public Health 2007, 97:1269-1274.

91. Krieger N, Carney D, Lancaster K, Waterman PD, Kosholeva A, Banaji M: Combining Explicit and Implicit Measures of Racial Discrimination in Health Research. Am J Public Health 2010, 100:1485-1492.

92. Sechrist GB, Swim JK, Stangor C: When Do the Stigmatized Make Attributions to Discrimination Occurring to the Self and Others? The Roles of Self-Presentation and Need for Control. J Personal Soc Psychol 2004, 87:111-122.

93. Mellor D, Bynon G, Maller J, Cleary F, Hamilton A, Watson L: The perception of racism in ambiguous scenarios. J Ethn Migr Stud 2001 27:473-488.

94. Kaiser CR, Major B: A Social Psychological Perspective on Perceiving and Reporting Discrimination. Law Soc Ing 2006, 31:801-830.

95. Bennett GG, Merritt MM, Edwards CL, Sollers JJ: Perceived Racism and Affective Responses to Ambiguous Interpersonal Interactions Among African American Men. Am Behav Sci 2004, 47:963-976.

96. Juang LP, Cookston JT: Acculturation, discrimination, and depressive symptoms among Chinese American adolescents: a longitudinal study. J Prim Prev 2009, 30:475-496.

97. Barnes LL, Mendes De Leon CF, Lewis TT, Bienias JL, Wilson RS, Evans DA: Perceived Discrimination and Mortality in a Population-Based Study of Older Adults. Am J Public Health 2008, 98:1241-1247.
98. Gee G, Walsemann K: Does health predict the reporting of racial discrimination or do reports of discrimination predict health? Findings from the National Longitudinal Study of Youth. Soc Sci Med 2009, 69:1676-1684.

99. McClelland GH, Judd CM: Statistical Difficulties of Detecting Interactions and Moderator Effects. Psychol Bull 1993, 114:376-390.

100. Fritz MS, MacKinnon DP: Required Sample Size to Detect the Mediated Effect. Psychol Sci (Wiley-Blackwell) 2007, 18:233-239.

101. Hair F, Black W, Babin B, Anderson R, Tatham R: Multivariate data analysis. 6 edition. Upper Saddle River, NJ: Pearson/Prentice Hall.; 2006.

102. Spatz C, Kardas E: Research methods: Ideas, techniques, \& reports New York, NY: McGraw-Hill; 2008.

103. Carver CS, Scheier MF, Segerstrom SC: Optimism. Clinical Psychology Review

104. Paradies Y, Chandrakumar L, Klocker N, Frere M, Webster K, Burrell M, McLean P: Building on our strengths: a framework to reduce race-based discrimination and support diversity in Victoria. Book Building on our strengths: a framework to reduce race-based discrimination and support diversity in Victoria City: Victorian Health Promotion Foundation; 2009, (Editor ed.^eds.)

\section{Pre-publication history}

The pre-publication history for this paper can be accessed here: http://www.biomedcentral.com/1471-2458/12/131/prepub

doi:10.1186/1471-2458-12-131

Cite this article as: Paradies and Cunningham: The DRUID study: racism and self-assessed health status in an indigenous population. BMC Public Health 2012 12:131.

\section{Submit your next manuscript to BioMed Central and take full advantage of:}

- Convenient online submission

- Thorough peer review

- No space constraints or color figure charges

- Immediate publication on acceptance

- Inclusion in PubMed, CAS, Scopus and Google Scholar

- Research which is freely available for redistribution

Submit your manuscript at www.biomedcentral.com/submit
C) Biomed Central 